\title{
Progress towards lightning control using lasers
}

\author{
Jérôme Kasparian \\ jerome.kasparian@unige.ch \\ Roland Ackermann \\ Yves-Bernard André \\ Grégoire Méchain \\ Guillaume Méjean \\ Bernard Prade \\ Philipp Rohwetter \\ Estelle Salmon \\ Kamil Stelmaszczyk \\ Jin Yu
}

\section{André Mysyrowicz \\ Roland Sauerbrey \\ Ludger Wöste}

Jean-Pierre Wolf

\begin{abstract}
Teramobile, Université de Lyon; Université Lyon 1; CNRS; LASIM UMR 5579, bât. A. Kastler, 43 Bd du 11 novembre 1918, F-69622 Villeurbanne Cedex, France

GAP, Université de Genève, 20 rue de l'École de Médecine, CH-1211 Genève 4, Switzerland

Teramobile, Université de Lyon; Université Lyon 1; CNRS; LASIM UMR 5579, bât. A. Kastler, 43 Bd du 11 novembre 1918, F-69622 Villeurbanne Cedex, France

Teramobile, Laboratoire d'Optique Appliquée, UMR CNRS 7639, ENSTA-Ecole Polytechnique, Centre de l'Yvette, Chemin de la Hunière, F-91761 Palaiseau Cedex, France

Teramobile, Laboratoire d'Optique Appliquée, UMR CNRS 7639, ENSTA-Ecole Polytechnique, Centre de 1'Yvette, Chemin de la Hunière, F-91761 Palaiseau Cedex, France

Teramobile, Université de Lyon; Université Lyon 1; CNRS; LASIM UMR 5579, bât. A. Kastler, 43 Bd du 11 novembre 1918, F-69622 Villeurbanne Cedex, France

Teramobile, Laboratoire d'Optique Appliquée, UMR CNRS 7639, ENSTA-Ecole Polytechnique, Centre de l'Yvette, Chemin de la Hunière, F-91761 Palaiseau Cedex, France

Teramobile, Institut für Experimentalphysik, Freie Universität Berlin, Arnimallee 14, D14195 Berlin, Germany

Teramobile, Université de Lyon; Université Lyon 1; CNRS; LASIM UMR 5579, bât. A. Kastler, 43 Bd du 11 novembre 1918, F-69622 Villeurbanne Cedex, France

Teramobile, Institut für Experimentalphysik, Freie Universität Berlin, Arnimallee 14, D14195 Berlin, Germany

Teramobile, Université de Lyon; Université Lyon 1; CNRS; LASIM UMR 5579, bât. A. Kastler, 43 Bd du 11 novembre 1918, F-69622 Villeurbanne Cedex, France

Teramobile, Laboratoire d'Optique Appliquée, UMR CNRS 7639, ENSTA-Ecole Polytechnique, Centre de l'Yvette, Chemin de la Hunière, F-91761 Palaiseau Cedex, France

Forschungszentrum Dresden - Rossendorf, Bautzner Landstrasse 128, 01328 Dresden, Germany
\end{abstract}

Teramobile, Institut für Experimentalphysik, Freie Universität Berlin, Arnimallee 14, D14195 Berlin, Germany

GAP, Université de Genève, 20 rue de l'École de Médecine, CH-1211 Genève 4, Switzerland

Lightning research needs on-demand lightning strikes, because of the random character of natural lightning. Lasers have been proposed as alternatives to the current technique using rocket-pulled wires, because they would expectedly provide more flexibility. However, highenergy, nanosecond lasers cannot provide long connected plasma channels. In contrast, we recently reported the triggering of electric events in thunderclouds using ultrashort laser pulses. Further improvements of the laser pulse sequence and experimental geometry are discussed. [DOI: 10.2971/jeos.2008.08035]

Keywords: lightning, ultrashort laser, self-guiding, laser filaments, plasma

\section{INTRODUCTION}

Attempts to provide natural rather than divine interpretations of lightning began in the $17^{\text {th }}$ Century with René Descartes, followed in the $18^{\text {th }}$ Century by Thomas-François Dalibard and Benjamin Franklin. The former demonstrated that lightning is an electrical phenomenon, in an experiment initially proposed by the latter, who also conceived the first lightning rod [1]. In the $20^{\text {th }}$ Century, photography and the cathode ray tube oscilloscope allowed the trajectory of lightning strikes to be observed, and the corresponding voltage and intensity to be measured, i.e. $\sim 100 \mathrm{MV}$ and $\sim 30 \mathrm{kA}$, respectively [2]. Today's instruments provide an even more precise view of the processes at play in the physics of lightning.

Lightning strikes occur after charges are generated by collisions between ice and/or water particles within thunderclouds, and separated by vertical winds, with speeds up to $20 \mathrm{~m} / \mathrm{s}$. The electric field originating from this separation between positive charges at the cloud top and negative charges 


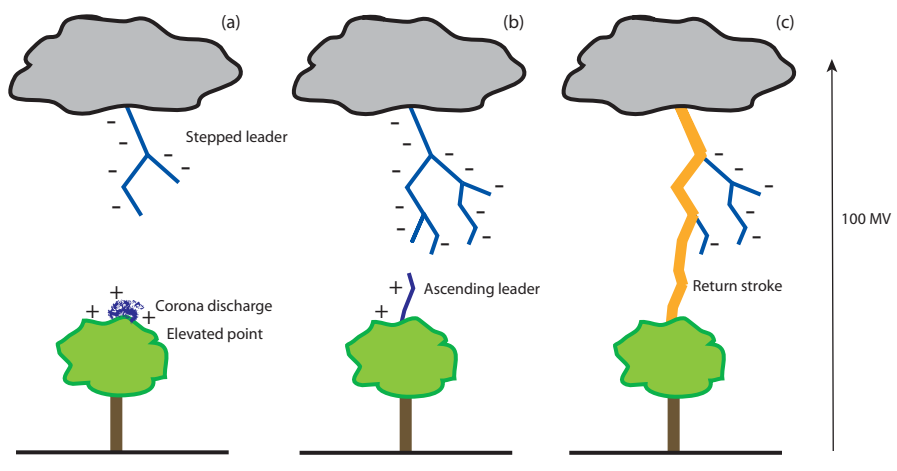

FIG. 1 Mechanism of lightning initiation: (a) stepped leader formation; (b) initiation of an upward leader; (c) return stroke

at its bottom reaches up to 10 to $15 \mathrm{kV} / \mathrm{m}$ at ground level, and $50 \mathrm{kV} / \mathrm{m}$ some hundreds of meters above. Such high field initiates corona discharges which develop into streamers, which in turn connect and form an ionized channel, or leader (Figure 1(a)). The leader progresses downwards in several branches, by steps of a few tens of meters, with typical rest times of $100 \mu$ s between two steps (Figure 1(b)). If a leader branch reaches close to an elevated point such as a tree, a building or a mountain ridge, an upward leader starts, propagates upwards and connects to the descending leader, allowing a return stroke, with a typical intensity of $30 \mathrm{kA}$, to flow from the ground to the cloud (Figure 1(c)). The return stroke lasts a few tenths of a second and constitutes the visible part of the lightning strike.

\section{ATTEMPTS TO TRIGGER LIGHTNING USING HIGH-ENERGY LASERS}

Lightning is a random process in both the spatial and temporal domains. But field experiments require lightning strikes at the very location of instruments, which moreover need synchronization. Therefore, they require some extent of control of the lightning strikes. Several groups [3,4] developed ondemand lightning initiation by rockets pulling a thin conducting wire, which triggers a lightning strike and guides it to the ground. Conducting wires sections as short as a few tens of meters proved almost as efficient as longer ones, and limit the perturbation to the lightning mechanism. However, rockets lack flexibility, since they cannot be aimed at specific cloud regions and are available in limited number.

Soon after their discovery, lasers were proposed as potential triggers for lightning, that could offer more flexibility than rockets, including beam steering and virtually continuous operation. Such proposition generated extensive work, both theoretical and experimental [5]. Laser sparks were typically produced by $\mathrm{CO}_{2}$ lasers, with energies up to several $\mathrm{kJ}$ [6] and a typical pulse duration of $50 \mathrm{~ns}$ [7]. Such high energy heats the channel up to $4000^{\circ} \mathrm{C}$, and therefore reduces the gas density to the $0.1 \mathrm{~atm}$ range, resulting in efficient air ionization. But the dense plasma generated by the leading edge of the pulse absorbs its tail, resulting in high pulse energy losses and blocking further propagation, hence preventing the generation of a connected plasma channel longer than a few meters.
Field experiments on the shore of the Sea of Japan in a period of intense winter low-cloud thunderstorms confirmed this limitation [8]. Three lasers were used. One $1 \mathrm{~kJ} \mathrm{CO}$ laser was focused on a dielectric target at the top of a $50 \mathrm{~m}$ high tower constructed on a $200 \mathrm{~m}$ high hill, while a second one was focused near to the generated ablation plume to form a $2 \mathrm{~m}$ long plasma spark. A third, ultraviolet laser produced a weakly ionized plasma channel slightly offset from the tower, intended to direct the leader to the cloud. The lasers were triggered when the initiation of cloud discharges, considered as the precursor of the descending lightning strikes, was detected. The authors reported two successful attempts, although the statistical significance of their result is not clear.

\section{CONTROL OF HIGH-VOLTAGE DISCHARGES USING ULTRASHORT LASERS}

The advent of lasers providing ultrashort, high-power pulses changed the perspective for laser-induced lightning. In contrast to longer pulses, ultrashort laser pulses in air form plasma channels, or self-guided filaments [9]-[13] with a length up to $100 \mathrm{~m}$ [14] at a distance from several meters up to several kilometres from the laser source [15]. This process originates from a dynamic balance between Kerr self-focusing and the defocusing effect of the free electrons of the plasma generated at the self-focus location. Steering the beam allows to aim the ionized plasma channel at the most active part of a thundercloud. Furthermore, filaments can propagate almost unperturbed in adverse conditions such as rain [16], fog [17], turbulence [18, 19] or reduced pressure [16], which makes them highly suitable for atmospheric applications.

Both infrared [20, 21] and ultraviolet [22] ultrashort laser pulses have been shown to trigger high-voltage discharges in strongly focused configurations. Later, the Teramobile laser [23] installed in a high-voltage facility generated self-guided filaments, which triggered (Figure 2) and guided 1.8 MV discharges over up to $4.5 \mathrm{~m}$ [24]-[26] (Figure 3) using $300 \mathrm{~mJ}$

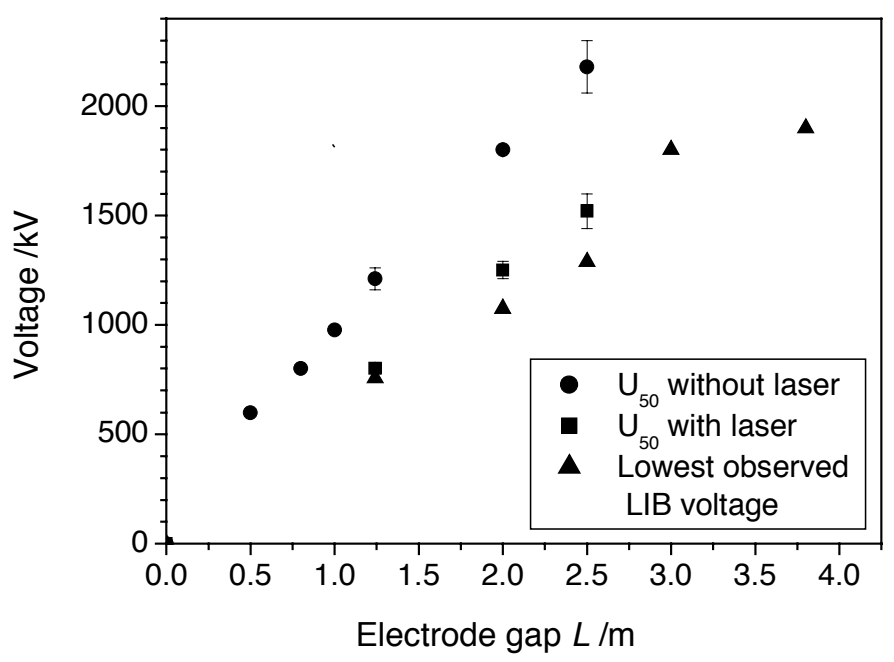

FIG. 2 Laser triggering of high-voltage discharges: Median breakdown voltage (U50) with and without laser. The lowest breakdown voltage observed (LIB) is also plotted [24]. 


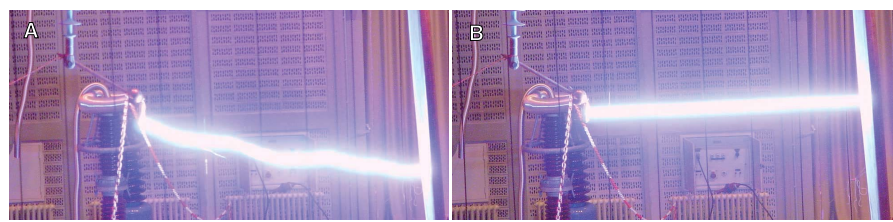

FIG. 3 Laser guiding of high-voltage discharges. (a) Free discharge over $3 \mathrm{~m}$, without laser filaments. Note the erratic path. (b) Straight discharge guided along laser filaments [25].

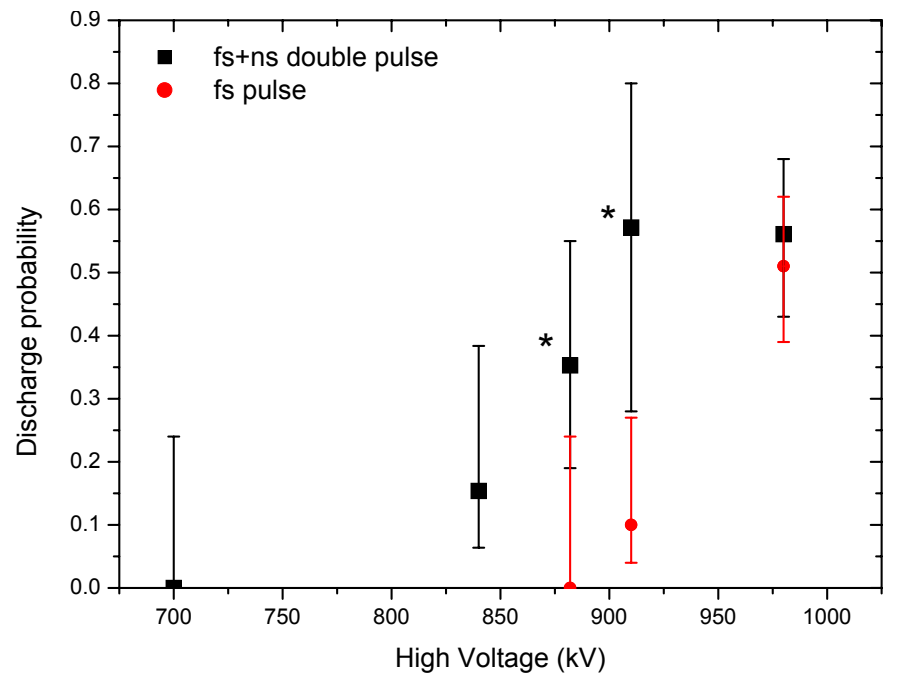

FIG. 4 Triggering probability of high-voltage discharges with both a single fs pulse alone and a dual (fs+ns) pulse with the maintaining pulse at $532 \mathrm{~nm}$. ${ }^{*}$ denotes a statistically significant effect of the maintaining laser for individual points [28].

pulses centered at $790 \mathrm{~nm}$. Even artificial rain does not prevent the laser filaments from triggering discharges [27]. Moreover, a subsequent YAG laser pulse of moderate energy (subJoule) at $532 \mathrm{~nm}$ increases the triggering effect of the infrared femtosecond laser [28, 29] (Figure 4) by extending the plasma lifetime, improving the scalability to the atmosphere. This approach relies on avalanche ionization, re-heating and photodetaching electrons of the plasma channel by subsequent pulses, either in the nanosecond [22] or in the femtosecond regime [30,31]. Although none of these processes alone has a significant contribution, they can contribute to the switching to a regime where increased electron density, more efficient Joule heating and reduced electron attachment efficiency at higher temperatures sustain each other in a positive feedback loop.

\section{FIELD EXPERIMENTS WITH FEMTOSECOND LASER FILAMENTATION}

Following the demonstration of both the capability of laser filaments to propagate in realistic atmospheric conditions and their ability to trigger high-voltage electric discharges, the effect of femtosecond plasma channels of moderate energy on thunderclouds was investigated during a field campaign [32] at the Langmuir Laboratory (New Mexico, USA, see Figure 5), which provides a fully equipped facility with high lightning occurrence.

The Teramobile laser [23] emitted a collimated beam, leaning

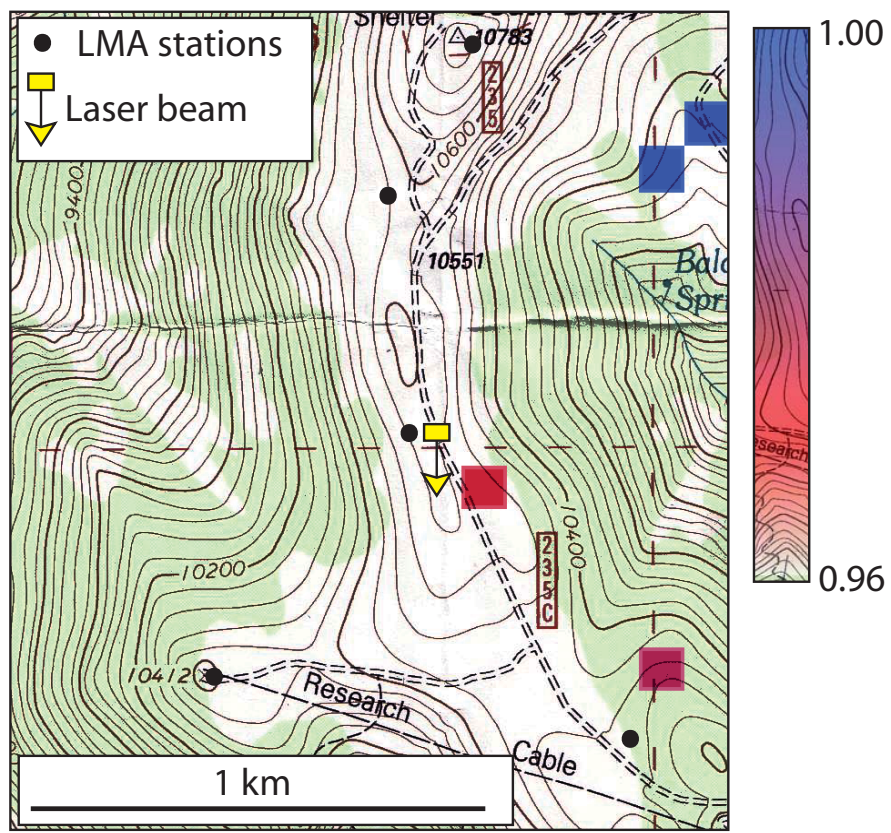

FIG. 5 Statistical confidence level of the electric events synchronized with the laser pulses during a thunderstorm on September 25,2004 . The colour scale is transparent below $96 \%$ (i.e. for error risks above $4 \%$ ), leaving the topographical background uncovered. Topographic background courtesy of US Ceological Survey.

southwards $70^{\circ}$ above horizontal from the ridge of South Baldy Peak, $3209 \mathrm{~m}$ above sea level, at a repetition rate of $10 \mathrm{~Hz}$. The laser beam diameter was $3 \mathrm{~cm}$, and the energy per pulse was $270 \mathrm{~mJ}$ at a central wavelength of $800 \mathrm{~nm}$. The laser pulses were negatively chirped to $600 \mathrm{fs}$ in order to generate multiple filamentation with significant ionization over a typical length of $100 \mathrm{~m}$, a few hundreds of meters above the ground. The data analysis focused on a total time of $250 \mathrm{~s}$ during two thunderstorms, when the electric field would have been sufficient to trigger lightning using rockets.

An array of five radiofrequency $(\mathrm{RF})$ receivers located within $1 \mathrm{~km}$ distance from the laser (see Figure 5) detected the electric activity in the atmosphere [33]. Triangulation based on the times of arrival of the RF pulses on the detectors yielded a location and time stamping of the cloud activity which generated them. Delay mismatches up to 300 ns were accepted between the detectors, to allow the detection of events distributed over a length up to $100 \mathrm{~m}$ (i.e. the expected filamentation length) along the laser beam.

Since the laser is fired independently from the electric activity in the clouds, and natural electric activity in clouds is a random process, we sought for temporal correlations between the electric events detected by the LMA and the laser pulses. A significant correlation appears as a strong indication of an effect of the laser, with a confidence level defined by a comparison between the number of observed synchronized events and the number of random events that would expectedly happen to be synchronized by pure chance.

Figure 5 displays the result of this statistical analysis for a storm on September 25, 2004. At the location of the laser filaments (arrow head) within the spatial resolution of the data processing, 30\% (3 out of 10) of the pulses are synchro- 
nized with the laser repetition rate. The probability to obtain the same number of synchronized events by chance is only $2.4 \%$, meaning that the statistical confidence level is as high as $97.6 \%$. The delay mismatch between the RF pulses detected on the different LMA detectors for some events correspond to some tens of meters, typical of spatially spread events, such as corona discharges at the tips of individual filaments within the bundle of multiple filaments. Similar results are obtained during the second thunderstorm, while no effect was observed when the electric field was low or negative.

These results suggest that a small fraction $(0.24 \%$, i.e. $\sim$ 1 event/minute) of the plasma filaments have initiated electric events in a strong positive (upward pointing) electric field [32]. This result constitutes a step towards laser-controlled lightning, but the low efficiency achieved in this experiment requires further development.

\section{OPTIMIZATION OF THE FILAMENT EFFECT IN THUNDERSTORMS}

The very limited effect of the plasma channel left behind by the filaments, which did not trigger lightning strikes to the ground, appears to be due to their low electron density as well as the limited plasma lifetime of $\sim 1 \mu \mathrm{s}[34,35]$, corresponding to an effective length on the meter-scale for a leader propagating at a speed of a few $10^{6} \mathrm{~m} / \mathrm{s}$ [24]. Since wires of a few tens of meters are sufficient for rocket triggering of lightning, the plasma lifetime has to be enhanced up to several tens of $\mu \mathrm{s}$. As discussed above, this may be achieved by emitting a pulse sequence, with a YAG laser pulse $[22,28,29]$ or a train of femtosecond pulses $[30,31]$ launched after the initial ultrashort pulse. The definition of the optimal pulse sequence is still an open question, relying on extensive modelling of the temporal evolution of the plasma channel created by the laser in an electric field [36]. Other available parameters include the pulse energy and beam profile. While the latter is difficult to control over long distances in the highly perturbed propagation conditions encountered in thunderstorms, higher pulse energies could yield more filaments over longer distances [37] thus possibly improving the effect of the laser on the electric field.

The emission geometry is also subject to optimization. Hints in this direction have recently been proposed [38]. This model considers filaments as passive conductors, which suddenly emerge from the space charge accumulated around the ground, as rockets do if their speed is sufficient, resulting in an enhanced electric field favourable for lightning initiation. The treatment of filaments as static conductors is supported by an estimation of $\mathrm{a} \sim 0.1 \mu$ s loading time of the RC circuit formed by the ground, filament, and cloud base. Such loading time is longer than the picosecond timescale of electron attachment, but shorter than the microsecond lifetime of the plasma channel. Therefore, filaments can be assumed to intercept all leaders in their vicinity, within a distance $r=10 I^{2 / 3} \sim 100 \mathrm{~m}$ for an intensity $I=30 \mathrm{kA}$ of the lightning strike [2]. Once it interacts with the descending leader and generates an upward positive leader, the plasma channel is considered to be stabilized by the current flowing through it [39].

Based on these assumptions, phenomenological Monte-Carlo simulations of a descending leader above a flat ground were used to illustrate the impact of several configuration parameters with and without tower [38]. Due to a limited region of influence and a poor duty cycle related to the short plasma lifetime as compared with typical repetition rates of terawatt lasers, a fixed, vertical laser beam triggered independently from the cloud activity appears to have a hardly measurable effect on the thundercloud. A few events at most may be accessible, which could explain the very small number of events observed during the Teramobile field campaign [32].

However, the flexibility of the laser technique could drastically improve this low efficiency. The laser beam could be triggered and steered according to a real-time detector, as used by Uchida et al. [8] to detect and locate the advent of descending leaders. This approach improves the duty cycle by a factor of 100 to 1000 , since all laser shots will then be able to intercept a descending leader. Moreover, the steering capability extends the volume of influence of the laser, and therefore increases the number of accessible descending leaders by a typical factor of 10, even for conservative filament heights of a few hundreds of meters [38]. Intercepting several tens to a few hundreds of shots in one single season therefore appears accessible. Such numbers are sufficient to achieve the statistical significance required for a field campaign to be conclusive. It could also constitute a quantitative improvement as compared with the yield of the rocket technique.

\section{CONCLUSION}

Although initiated 50 years ago, the effort to control lightning using lasers has not yet reached its goal of triggering and guiding lightning strikes on demand to the ground. However, recent results obtained with the femtosecond-terawatt Teramobile laser renew the expectations that ultrashort laser pulses may be good candidates to achieve this challenge. Further improvement requires optimized plasma filaments generated by the ultrashort laser pulses. In particular, pulse sequences, as well as a higher pulse power, are expected to enhance both the electron density and plasma lifetime. Active triggering and steering of the laser upon the detection of leader initiation in the clouds shall also improve dramatically the volume accessible to the filaments, as well as their duty cycle. Macroscopic number of triggered events could therefore be expected in a near future.

\section{ACKNOWLEDGEMENTS}

This work has been performed in the framework of the Teramobile collaboration (www.teramobile.org), funded jointly by the CNRS, DFG, French and German ministries of Foreign affairs, Agence Nationale de la Recherche (ANR, grant \# NT051_43175), Fonds national suisse de la recherche scientifique (FNS, grants \#200021-111688/1 and 200021-116198/1), and the 
Swiss Secrétariat d'État à l'Éducation et à la Recherche (COST P18 action C06.0114).

\section{References}

[1] E. Philip Krider, "Benjamin Franklin and the First Lightning Conductors" Proc. Int. Comm. Hist. Met. 1, 1-13 (2004).

[2] C. Gary, La foudre: nature, histoire, risques et protection (Dunod, Paris, 2004).

[3] R. Fieux, C. Gary, and P. Hubert, "Artificially Triggered Lightning above Land" Nature 257, 212-214 (1975).

[4] V. A. Rakov, M. A. Uman, and K. J. Rambo, "A review of ten years of triggered-lightning experiments at Camp Blanding, Florida" Atmos. Res. 76, 503-517 (2005).

[5] E. M. Bazelyan, and Yu P. Raizer, "The mechanism of lightning attraction and the problem of lightning initiation by lasers" PhysUsp+ 43, 701 (2000).

[6] V. Apollonov et al. AHPLA'99 Paper 3886-34

[7] M. Miki, Y. Aihara, and T. Shindo, "Development of long gap discharges guided by a pulsed $\mathrm{CO}_{2}$ laser" J. Phys. D Appl. Phys 26, 1244-1252 (1993).

[8] S. Uchida, Y. Shimada, H. Yasuda, S. Motokoshi, C. Yamanaka, T. Yamanaka, Z. Kawasaki, and K. Tsubakimoto, "Laser-triggered lightning in field experiments" J. Opt. Technol. 66, 199-202 (1999).

[9] A. Braun, G. Korn, X. Liu, D. Du, J. Squier, and G. Mourou, "Selfchanneling of high-peak-power femtosecond laser pulses in air" Opt. Lett. 20, 73-75 (1995).

[10] S. L. Chin, S. A. Hosseini, W. Liu, Q. Luo, F. Theberge, N. Akozbek, A. Becker, V. P. Kandidov, O. G. Kosareva, and H. Schroeder, "The propagation of powerful femtosecond laser pulses in optical media: physics, applications, and new challenges" Can. J. Phys. 83, 863-905 (2005).

[11] L. Bergé, S. Skupin, R. Nuter, J. Kasparian, and J.-P. Wolf, “Ultrashort filaments of light in weakly-ionized, optically-transparent media" Rep. Prog. Phys. 70, 1633-1713 (2007).

[12] A. Couairon, and A. Mysyrowicz, "Femtosecond filamentation in transparent media" Phys. Rep. 441, 47-189 (2007).

[13] J. Kasparian, and J.-P. Wolf, "Physics and applications of atmospheric nonlinear optics and filamentation" Opt. Express 16, 466493 (2008).

[14] B. La Fontaine, F. Vidal, Z. Jiang, C. Y. Chien, D. Comtois, A. Desparois, T. W. Johnson, J.C. Kieffer, and H. Pépin, "Filamentation of ultrashort pulse laser beams resulting from their propagation over long distances in air" Phys. Plasmas 6, 1615-1621 (1999).

[15] M. Rodriguez, R. Bourayou, G. Méjean, J. Kasparian, J. Yu, E. Salmon, A. Scholz, B. Stecklum, J. Eislöffel, U. Laux, A. P. Hatzes, R. Sauerbrey, L. Wöste, and J.-P. Wolf, "Kilometer-range non-linear propagation of femtosecond laser pulses" Phys. Rev. E 69, 036607 (2004).

[16] G. Méchain, G. Méjean, R. Ackermann, P. Rohwetter, Y.-B. André, J. Kasparian, B. Prade, K. Stelmaszczyk, J. Yu, E. Salmon, W. Winn, L. A. V. Schlie, A. Mysyrowicz, R. Sauerbrey, L. Wöste, and J.-P. Wolf, "Propagation of fs-TW laser filaments in adverse atmospheric conditions" Appl. Phys. B 80, 785-789 (2005).

[17] G. Méjean, J. Kasparian, J. Yu, E. Salmon, S. Frey, J.-P. Wolf, S. Skupin, A. Vinçotte, R. Nuter, S. Champeaux, and L. Bergé, "Multifilamentation transmission through fog" Phys. Rev. E 72, 026611 (2005).
[18] R. Ackermann, G. Méjean, J. Kasparian, J. Yu, E. Salmon, and J.-P. Wolf, "Laser filaments generated and transmitted in highly turbulent air" Opt. Lett. 31, 86-88 (2006).

[19] R. Salamé, N. Lascoux, E. Salmon, J. Kasparian, and J. P. Wolf, "Propagation of laser filaments through an extended turbulent region" Appl. Phys. Lett. 91, 171106 (2007).

[20] H. Pépin, D. Comtois, F. Vidal, C. Y. Chien, A. Desparois, T. W. Johnston, J. C. Kieffer, B. La Fontaine, F. Martin, F. A. M. Rizk, C. Potvin, P. Couture, H. P. Mercure, A. Bondiou-Clergerie, P. Lalande, and I. Gallimberti, "Triggering and guiding high-voltage large-scale leader discharges with sub-joule ultrashort laser pulses" Phys. Plasmas 8, 2532-2539 (2001).

[21] D. Comtois, C. Y. Chien, A. Desparois, F. Cérin, G. Jarry, T. W. Johnston, J. C. Kieffer, B. La Fontaine, F. Martin, R. Mawassi, H. Pépin, F. A. M. Rizk, F. Vidal, P. Couture, H. P. Mercure, C. Potvin, A. Bondiou-Clergerie, and I. Callimberti, "Triggering and guiding leader discharges using a plasma channel created by an ultrashort laser" Appl. Phys. Lett. 76, 819-821 (2000).

[22] P. Rambo, J. Schwartz, and J.-C. Diels, "High-voltage electrical discharges induced by an ultrashort-pulse UV laser system" J. Opt. A - Pure Appl. 0p. 3, 146-158 (2001).

[23] H. Wille, M. Rodriguez, J. Kasparian, D. Mondelain, J. Yu, A. Mysyrowicz, R. Sauerbrey, J.-P. Wolf, and L. Wöste, "Teramobile: a mobile femtosecond-terawatt laser and detection system" Eur. Phys. J.-Appl. Phys. 20, 183-190 (2002).

[24] M. Rodriguez, R. Sauerbrey, H. Wille, L. Wöste, T. Fujii, Y.-B. André, A. Mysyrowicz, L. Klingbeil, K. Rethmeier, W. Kalkner, J. Kasparian, E. Salmon, J. Yu, and J.-P. Wolf, "Megavolt discharges triggered and guided with laser filaments" Opt. Lett. 27, 772-774 (2002).

[25] J. Kasparian, M. Rodriguez, G. Méjean, J. Yu, E. Salmon, H. Wille, R. Bourayou, S. Frey, Y.-B. André, A. Mysyrowicz, R. Sauerbrey, J.-P. Wolf, and L. Wöste, "White-Light Filaments for Atmospheric Analysis" Science 301, 61-64 (2003).

[26] R. Ackermann, G. Méchain, G. Méjean, R. Bourayou, M. Rodriguez, K.Stelmaszczyk, J. Kasparian, J. Yu, E. Salmon, S. Tzortzakis, Y.-B. André, J.-F. Bourrillon, L. Tamin, J.P. Cascelli, C. Campo, C. Davoise, A. Mysyrowicz, R. Sauerbrey, L. Wöste, and J.-P. Wolf, "Wolf, Influence of negative leader propagation on the triggering and guiding of high voltage discharges by laser filaments" Appl. Phys. B. 82, 561-566 (2006).

[27] R. Ackermann, K. Stelmaszczyk, P. Rohwetter, G. Méjean, E. Salmon, J. Yu, J. Kasparian, G. Méchain, V. Bergmann, S. Schaper, B. Weise, T. Kumm, K. Rethmeier, W. Kalkner, J.P. Wolf, and L. Wöste, "Triggering and guiding of megavolt discharges by laser-induced filaments under rain conditions" Appl. Phys. Lett. 85, 5781-5783 (2004).

[28] G. Méjean, R. Ackermann, J. Kasparian, E. Salmon, J. Yu, J.-P. Wolf, K. Rethmeier, W. Kalkner, P. Rohwetter, K. Stelmaszczyk, and L. Wöste, "Improved laser triggering and guiding of megavolt discharges with dual fs-ns pulses" Appl. Phys. Lett. 88, 021101 (2006).

[29] X. M. Zhao, J.-C. Diels, C. Y. Wang, and J. M. Elizondo, "Femtosecond ultraviolet laser pulse induced lightning discharges in gases" IEEE J. Quantum Elect. 31, 599-612 (1995).

[30] Z. Hao, J. Zhang, Y. T. Li, X. Lu, X. H. Yuan, Z. Y. Zheng, Z. H. Wang, W. J. Ling, Z. Y. Wei, "Prolongation of the fluorescence lifetime of plasma channels in air induced by femtosecond laser pulses" Appl. Phys. B 80, 627-630 (2005).

[31] H. Yang, J. Zhang, Y. Li, J. Zhang, Y. Li, Z. Chen, H. Teng, Z. Wei, and Z. Sheng, "Characteristics of self-guided laser plasma channels generated by femtosecond laser pulses in air" Phys. Rev. E 66, 016406 (2002). 
[32] J. Kasparian, R. Ackermann, Y.-B. André, G. Méchain, G. Méjean, B. Prade, P. Rohwetter, E. Salmon, K. Stelmaszczyk, J. Yu, A. Mysyrowicz, R. Sauerbrey, L. Wöste, and J.P. Wolf, “Electric events synchronized with laser filaments in thunderclouds" Opt. Express 16, 5757 (2008).

[33] W. Rison, R. J. Thomas, P. R. Krehbiel, T. Hamlin, and J. Harlin, "A GPS-based three-dimensional lightning mapping system: Initial observations in central New Mexico" Geophys. Res. Lett. 26, 35733576 (1999).

[34] B. La Fontaine, F. Vidal, D. Comtois, C.-Y. Chien, A. Deparois, T. W. Johnston, J.C. Kieffer, H. P. Mercure, H. Pépin, and F. A. M. Rizk, "The influence of electron density on the formation of streamers in electrical discharges triggered with ultrashort laser pulses" IEEE T. Plasma Sci. 27, 688-700 (1999).

[35] S. Tzortzakis, B. Prade, M. Franco, and A. Mysyrowicz, "Time evolution of the plasma channel at the trail of a self-guided IR femtosecond laser pulse in air" Opt. Commun. 181, 123-127 (2000).
[36] T. B. Petrova, H. D. Ladouceur, and A. P. Baronavski, “Numerical modeling of the electrical breakdown and discharge properties of laser-generated plasma channels" Phys. Rev. E 76, 066405 (2007).

[37] P. Béjot, L. Bonacina, J. Extermann, M. Moret, J. P. Wolf, R. Ackermann, N. Lascoux, R. Salamé, E. Salmon, J. Kasparian, L. Bergé, S. Champeaux, C. Guet, N. Blanchot, 0. Bonville, A. Boscheron, P. Canal, M. Castaldi, 0. Hartmann, C. Lepage, L. Marmande, E. Mazataud, G. Mennerat, L. Patissou, V. Prevot, D. Raffestin, and J. Ribolzi, “32 Terawatt Atmospheric White-Light Laser" Appl. Phys. Lett. 90, 151106 (2007).

[38] J. Kasparian, and J.-P. Wolf, "On lightning control using lasers" Prog. Ultra. Int. Laser Sci. $\mathbf{5}$ to be published.

[39] T. B. Petrova, H. D. Ladouceur, and A. P. Baronavski, "Nonequilibrium dynamics of laser-generated plasma channels" Phys. Plasmas 15, 053501 (2008). 